\title{
Aquém da biopolítica: a parte (sem parte) de Jacques Rancière
}

\author{
Before biopolitics: the (no) part of Jacques Rancière
}

\begin{abstract}
Eduardo Pellejero
Doutor em Filosofia Contemporânea pela Faculdade de Letras da Universidade de Lisboa, professor da Universidade Federal do Rio Grande do Norte, Natal, RN - Brasil, e-mail: edupellejero@gmail.com
\end{abstract}

\section{Resumo}

Aquém da biopolítica têm pelo menos dois sentidos quando nos aproximamos da obra de Jacques Rancière. Refere, por um lado, o enclausuramento da política no domínio do que ele denomina de polícia, por parte de certas formas da filosofia contemporânea, a conta de uma relação de uma copertença entre o poder e a vida que daria conta do funcionamento das sociedades modernas - nesse sentido, aquém significa uma insuficiência na colocação da questão, o fato de reduzir o problema da política à questão das relações de poder ${ }^{1}$. Mas aquém da política refere, por outro lado, a postulação contraintuitiva da política enquanto processo específico, aquém de toda a partilha policial do sensível, isto é, da política entendida enquanto administração efetiva do comum, seja sob suas figuras históricas hegemónicas, seja sob as suas formas menores emergentes - nesse sentido, aquém diz respeito a um espaço transcendental no qual é possível

1 "A política não é feita de relações de poder, é feita de relações de mundos" (RANClÈRE, 1996, p. 54). 
continuar a colocar a questão da emancipação universal além de qualquer superstição historicista, mas também além de qualquer tentativa de redução da política à ética. Explorar o alcance e os limites desses dois sentidos da reserva crítica de Rancière em relação à questão da biopolítica é o modesto objeto deste artigo.

Palavras-chave: Rancière. Biopolítica. Política. Polícia. Emancipação.

\section{Abstract}

Before biopolitics has two meanings when we approach the work of Jacques Rancière. First, it means the imprison of politics in the domain of what he calls police by some forms of contemporary philosophy, in the name of a relation of implication between power and life in modern societies - in that sense, before means the failure of the question on politics by reducing politics to power. But before also means Rancière contra-intuitive comprehension of politics as specific process, before any partition of the sensible - in that sense, before refers a kind of transcendental space where it is still possible to talk about universal emancipation, beyond any historicist superstition, but also beyond any attempt to reduce politics to ethics. This paper aims to explore the limits of those two elements of the critical position of Rancière in relation to the problem of biopolitics.

Keywords: Rancière. Biopolitics. Politics. Police. Emancipation.

A confrontação com os discursos que tematizam o biopoder e a biopolítica é tardia na obra de Rancière, e não surge em seus textos principais de forma direta (a relação da política e da vida na leitura de Arendt, pelo contrário, perpassa de forma mais ou menos constante sua reflexão, e já é denunciada explicitamente em Nas bordas do político, $\left.1990^{1}\right)$. Sua intervenção no debate, em todo o caso, em certa medida forçada por meio de entrevistas do grupo associado à revista Multitudes²,

10 confronto com Arendt é especialmente interessante no texto que Rancière dedica à questão dos direitos do homem (RANCIÈRE, 2004).

2 Na entrevista conduzida por Eric Alliez, tudo começa pela tentativa de enquadrar Rancière no horizonte do pensamento sobre a biopolítica, interpretando o par conceitual política/polícia em termos de duas formas de vida (RANCIÈRE, 2010).

Rev. Filos., Aurora, Curitiba, v. 25, n. 37, p. 35-55, jul./dez. 2013 
está ligada ao que Rancière identifica como uma sobredeterminação da política pela ontologia, e cuja análise desenvolvera sob o conceito de arquipolítica em $O$ desentendimento (1995) ${ }^{3}$. Perante a celebração generalizada do retorno da filosofia política, Rancière manifestava então uma reserva chamativa, identificando, nesse fenômeno, menos uma redescoberta filosófica da pureza da política (durante muito tempo reduzida à máscara das relações sociais pelo marxismo) que um esvaziamento da política pela filosofia (num sentido próximo, ainda que não idêntico, ao denunciado por Benjamin, na Alemanha nazista, a mãos da estética).

A vitalidade demostrada pela filosofia política nas últimas décadas, em grande medida consequência da sua redefinição a partir de uma ontologia da vida cujas formas se desdobram em projetos de diversos signos - da genealogia do biopoder foucaultiana à fundamentação negriana de uma biopolítica revolucionária, e da delimitação arendtiana da vida econômica e da vida política à filosofia da história de tom niilista que Agamben reconstrói a partir das noções de soberania e vida nua - , a vitalidade demostrada pela filosofia política, digo, constitui para Rancière uma deriva dessa ordem. Procurando remeter a fundação da política a modos de vida ou formas de existência (como é o caso em Aristóteles, que estabelece uma distinção entre os seres dotados de voz e os seres dotados de linguagem), o pensamento filosófico incorre num círculo vicioso, não oferecendo a descrição falsa de um fenômeno verdadeiro, mas oferecendo a descrição verdadeira de um epifenômeno ${ }^{4}$. Desconhecendo uma oposição fundamental, não entre dois modos de vida, mas entre duas partilhas do sensível, entre duas estruturações do mundo ${ }^{5}$ (a policial e a política), o pensamento biopolítico passa por alto que a política (e a sua impugnação da administração

3 Em 0 desentendimento, Rancière argumenta que os filósofos políticos de todas as épocas, de Platão a Marx, e de Aristóteles a Arendt, sempre tentaram substituir a desordem própria da política pela ordem hierárquica da filosofia, remitindo a política a princípios antropológicos, metafísicos ou religiosos. Para uma compreensão da evolução do pensamento político de Rancière (PELLEJERO, 2009).

4 "A simples oposição entre os animais lógicos e os animais fônicos não é pois, de forma alguma, o dado sobre o qual se funda a política" (RANCIÈRE, 1996, p. 35).

5 Isto é, entre duas maneiras de dividir o espaço e o tempo, de ver e falar de objetos comuns, de ouvir ou ignorar os sujeitos falam de tais objetos. 
policial do comum) existe apenas como suplemento de qualquer forma de bios, de qualquer forma de subjetividade constituída, de qualquer esfera de existência identificável (RANCIÈRE 2010, p. 76)

Noutras palavras, a reflexão política não gira em torno de modos de vida, como poderiam ser a vida nua e a vida qualificada, a vida do animal laborans e a do homo politicus etc., mais em torno de duas formas de partilha do sensível, que, aquém das apostas do biopoder e das tentativas de articular uma alternativa biopolítica, Rancière denomina de política e polícia (indo de encontro ao nosso modo habitual de compreender a política, isto é, chamando de polícia o que habitualmente pensamos sob a categoria do político ${ }^{7}$ ).

Chamamos geralmente pelo nome de política o conjunto dos processos pelos quais se operam a agregação e o consentimento das coletividades, a organização dos poderes, a distribuição dos lugares e funções e os sistemas de legitimação dessa distribuição. Proponho dar outro nome a essa distribuição e ao sistema dessas legitimações. Proponho chamá-la de polícia (RANCIÈRE 1996, p. 41).

É verdade que, nisso, Rancière retoma uma noção explorada por Foucault no próprio contexto do nascimento da biopolítica, mas segundo uma estratégia de apropriação que a separa "da associação habitual polícia/aparelho repressivo e também da problemática foucaultinana de disciplinarização dos corpos - ou da 'sociedade de vigilância"' (RANCIÈRE, 2010, p. 78). Rancière parece extrair da noção foucaultiana de polícia o seu duplo transcendental, enquanto princípio de partilha do sensível, contagem totalizante da situação, ordem do visível e do dizível - caracterizada pela adequação imaginária dos lugares, das funções e das maneiras de ser, assim como pela ausência de vazios e

\footnotetext{
6 Uma das típicas cenas às quais Rancière remete a sua hipótese de que a política não se funda numa forma específica de vida, mas, pelo contrário, é o processo pelo qual uma forma de vida passa a ser considerada (tornada visível, audível, competente) no mundo comum, é o de Olympe de Gouge (RANCIÈRE, 2004, p. 304).

7 "Há portanto, de um lado, essa lógica que conta as parcelas unicamente das partes, que distribui os corpos no espaço de sua visibilidade ou de sua invisibilidade e põe em concordância os modos do ser, os modos do fazer e os modos do dizer que convém a cada um. E há a outra lógica, aquela que suspende essa harmonia pelo simples fato de atualizar a contingência da igualdade, nem aritmética nem geométrica, dos seres falantes quaisquer" (RANCIÈRE, 1996, 41).
}

Rev. Filos., Aurora, Curitiba, v. 25, n. 37, p. 35-55, jul./dez. 2013 
suplementos - a partir da qual são definidas, num segundo momento, as estratégias e as técnicas de poder (RANCIÈRE, 2010, p. 300).

A polícia é assim, antes de mais nada, uma ordem dos corpos que define as divisões entre os modos do fazer, os modos de ser e os modos do dizer, que faz que tais corpos sejam designados por seu nome para tal lugar e tal tarefa; é uma ordem do visível e do dizível que faz com que essa atividade seja visível e outra não o seja, que essa palavra seja entendida como discurso e outra como ruído. É, por exemplo, uma lei de polícia que faz tradicionalmente do lugar de trabalho um espaço privado não regido pelos modos do ver e dizer próprios do que se chama o espaço público, onde o ter parcela do trabalhador é estritamente definido pela remuneração de seu trabalho. A polícia não é tanto uma 'disciplinarização' dos corpos quanto uma regra de seu aparecer, uma configuração das ocupações e das propriedades dos espaços em que essas ocupações são distribuídas (RANCIÈRE, 1996, p. 42).

Nos trabalhos de Foucault sobre a governabilidade, a polícia não constituía apenas uma instituição ou um mecanismo no seio do Estado, mas uma técnica do governo, própria do Estado:

o que, até o final do Antigo Regime, se denominava polícia não era, ou não era apenas, a instituição policial; era o conjunto dos mecanismos pelos quais eram asseguradas a ordem, o crescimento canalizado das riquezas e as condições de manutenção da saúde 'em geral' (FOUCAULT, 1994, p. 17 grifo nosso).

Foucault diz que essa nova configuração do poder (que enquanto tal não aparece até meados do século XVII), não é nem judiciária, nem militar, nem completamente política, e se encontra ligada à necessidade capitalista de que todos os indivíduos sejam vigiados ao próprio nível da sua integração às normas do trabalho, em ordem a que, enquanto seres vivos, produzam mais força. Polícia designa, nesse sentido, o novo domínio no qual o poder político e administrativo do Estado vai concentrar sua intervenção (FOUCAULT, 1994, p. 150); seu objeto estratégico é o próprio homem, em suas relações com o próprio corpo e com os outros homens, com os territórios e as coisas, com a propriedade e com a produção etc. (CASTRO, 2004). 
Em resumo, o homem e tudo o que se encontra ligado à sua felicidade. Nessa mesma medida, a noção foucaultiana de polícia constitui "um dispositivo social onde se conjugam o médico, o assistencial e o cultural" (RANCIÈRE, 1996, p. 41), manifestando uma significativa proximidade com a constituição histórica do biopoder, isto é, com esse deslocamento estratégico que faz da vida - dos corpos dos indivíduos ao fluxo das populações - um objeto dos investimentos do poder, da sua administração, controlo e/ou disciplinamento.

Rancière fará dessa ligação o centro dos seus ataques aos discursos que problematizam o biopoder, na medida em que estes se situariam aquém da política, no domínio duma análise restrita do exercício do poder, uma análise que se limitaria a considerar a partilha policial dos corpos e das agregações dos corpos, uma análise que diria apenas respeito aos efeitos de poder na individualização da vida e na socialização das populações. Todavia, Rancière deduzirá polemicamente que, na medida em que a problemática do biopoder se encontra sobredeterminada pela análise do exercício do poder, essa distância que a separa da política não pode ser desfeita sem reconfigurar os termos do problema, sem deslocar a perspectiva da aproximação. Reduzidos a uma teoria do poder e/ou a uma investigação dos espaços da sua legitimidade e funcionamento, os discursos que tematizam o biopoder não vão além da esfera da polícia, não chegam a colocar jamais de forma própria a questão política, que não se define pelo exercício do poder (RANCIÈRE, 2001), razão pela qual a noção de biopolítica é sempre vaga e confusa.

Há certo paradoxo em se querer inverter o polêmico dispositivo de Foucault, visando afirmar um enraizamento vitalista crucial da política. Pois, se a ideia de biopoder é clara, a de biopolítica é confusa. Uma vez que tudo o que Foucault menciona, situa-se no espaço daquilo que eu denomino polícia. Se Foucault pode falar, indiferentemente, em biopoder e em biopolítica, é porque seu pensamento sobre política foi construído em torno da questão do poder, uma vez que jamais esteve teoricamente interessado na questão da subjetivação política (RANCIÈRE, 2010, p. 77).

Rev. Filos., Aurora, Curitiba, v. 25, n. 37, p. 35-55, jul./dez. 2013 
A leitura que Rancière faz de Foucault é certamente contestável ${ }^{8}$, e voltaremos a ela, mas o seu valor é menos hermenêutico que polêmico, na medida em que se encontra associada à tentativa de denunciar a redução da política à questão do exercício do poder; redução que, nas apropriações contemporâneas do dispositivo foucaultiano, define genericamente as duas linhas maiores de desenvolvimento do que entendemos por 'biopolítica': 1) o solapamento do poder soberano e a vida nua caracterizado por Giorgio Agamben, e 2) a ontologia vitalista das multidões nas condições do império desenvolvida por Michel Hardt e Tony Negri (mas não só).

\section{$* * *$}

Em primeiro lugar, Rancière se confronta com a consideração agambeniana do biopoder enquanto modo de exercer a soberania. Sempre segundo Rancière, a aproximação de Agamben à questão tem por resultado uma construção onto-teológico-política que deduz, a partir das relações da vida com o poder implícitas no conceito de soberania, a totalidade das configurações da partilha do sensível que podemos identificar nos últimos cem anos nas nossas sociedades (desde os campos de extermínio nazistas até as democracias contemporâneas). Certamente, a entrada da vida biológica na ordem política tem como resultado a inscrição do elemento mais básico da existência nas malhas do poder, constituindo o acontecimento decisivo da modernidade e transformando as categorias políticas e filosóficas tradicionais (LAZZARATO, 2000). Mas enquanto, para Foucault, o dispositivo biopolítico (inclusive nas suas configurações mais 'negativas', como no caso da limpeza étnica) implicava sempre uma componente 'positiva' de administração da vida (como no caso da eugenia) que os distanciava dos dispositivos soberanos de administração da morte, para Agamben a administração da vida foucaultiana se solapa com

8 Para começar, quando Rancière fala de uma ausência de interesse pela subjetivação política em Foucault, desestima qualquer valor político da tematização foucaultiana da subjetividade, que na sua interpretação se restringiria à ética. Para um questionamento dessa interpretação ver TASSIN, 2012; LAZZARATO, 2000. 
o estado de exceção schmittiano, apagando a oposição entre poder soberano e biopoder, deixando pouco ou nenhum espaço para a interrupção política dessa partilha do sensível, na qual a vida só é libertada das malhas do poder quando abandonada à morte. Da análise agambeniana seguem-se certos corolários paradoxais: o estado de exceção é o conteúdo real das nossas democracias, os direitos humanos são a figura que assinala a violência infringida sobre a vida biológica pela vida política, somos todos refugiados num campo. Rancière (2004, p. 301) escreve:

Qualquer diferença entre democracia e totalitarismo se desvanece, qualquer prática política está condenada a ser pega na armadilha biopolítica. [...] A política é reduzida ao poder, um poder que é crescentemente assimilado a um irresistível destino histórico-ontológico do qual só Deus parece poder livrar-nos.

A vida nua, exposta sem reservas ao poder soberano, encontra-se efetivamente aquém da política (tal como definida por Rancière). Como assinala o próprio Agamben, nas condições do estado de exceção permanente ao qual dá lugar o biopoder, sobredeterminada a humanidade até os seus fundamentos biológicos por estruturas totalizantes, a teoria e a práxis política só podem apresentar-se aos nossos olhos nas formas do negativo, aprisionadas e imóveis, a uma distância insuperável de qualquer forma de política emancipatória. Nesse sentido, o biopoder agambeniano constitui, para Rancière, uma forma atualizada do niilismo heideggeriano (estrategicamente permeado pela filosofia de Hannah Arendt ${ }^{9}$ ).

Qualquer tipo de reivindicação de direitos [...] é assim encerrada por princípio na mera polaridade da vida nua e o estado de exceção. Essa polaridade aparece como uma espécie de destino ontológico: cada um de nós se encontraria na situação do refugiado num campo (RANCIÈRE, 2004, p. 301).

9 Para melhor apreciação da posição de Rancière em relação às críticas de Arendt e Agamben aos direitos humanos, ver: HEMEL, 2008. Quanto aos elementos da filosofia arendtiana que permeiam a obra de Rancière, ver: TASSIN, 2012.

Rev. Filos., Aurora, Curitiba, v. 25, n. 37, p. 35-55, jul./dez. 2013 
Certamente vivemos em ordens policiais oligárquicas, regidos por princípios de desigualdade, e, em grande medida, essas ordens encontram-se perpassadas pelos dispositivos do biopoder (e, em casos extremos, por articulações que expõem sem reservas a vida nua ao poder soberano). Rancière poderia estar de acordo com tudo isso, mas em termos gerais nós não vivemos em campos (RANCIÈRE, 2005, p. 81). A crítica de Rancière vai ao encontro desse diagnóstico, e está associada a uma recuperação de um conceito de política (e de democracia) que, na medida em que aspira a dar conta da possibilidade da nossa desincorporação em relação aos regimes nos quais vivemos, relança mais uma vez o sonho preterido da emancipação universal.

$* * *$

Em segundo lugar, Rancière dialoga, a uma distância crítica, com a tentativa de atribuir um conteúdo positivo à biopolítica, ora a partir de modos não estatais de governo e administração da vida, ora a partir de uma ontologia da vida que identifica a questão da subjetividade política com a questão das formas de individuação. A biopolítica confunde-se, então, segundo Rancière, com uma transformação espiritual ou transfiguração da vida (retomando nisso o modelo dos programas das vanguardas históricas, que identificavam a realização da arte com a sua própria supressão na elaboração de novas formas de vida), e cuja consequência imediata é a dissolução da política na tentativa de articular um novo poder constituinte.

Acho que isso ainda se encontra vivo na visão contemporânea de Hardt e Negri sobre o comunismo franciscano de multidões, implantado através do poder irresistível das redes globais, que fará explodir as fronteiras do Império. Em todos esses casos, a política e a arte realizam a sua autossupressão em benefício de uma nova forma de vida indivisa (RANCIÈRE, 2006).

A política é solapada então pela ideia de uma sociedade nova, cujos elementos já se encontrariam formados no seio mesmo da sociedade atual. No caso de Hardt e Negri, a esperança da refundação do 
comunismo a partir da potência das multidões se apoia no investimento cada vez mais direto do poder na vida dos indivíduos e das coletividades, e nas formas de produção imateriais próprias da sua inteligência coletiva, que nem sequer necessitam ser expropriadas (tal é a boa nova) para fazer explodir a ordem do Império: todo o que é necessário é uma autoafirmação ethopoiética.

Rancière é irredutível nisso. Interrogado por Eric Alliez (RANCIÈRE, 2010, p. 79) sobre a possibilidade de pensar o conceito de biopolítica a partir de uma espécie de inversão do biopoder, isto é, enquanto forma de articulação de uma resistência da vida social em relação aos dispositivos próprios do capitalismo, a sua resposta é categórica: não há qualquer possibilidade de articular uma passagem entre o biopoder (enquanto modo de exercício do poder) e a política (enquanto modo próprio de des-subjetivação política que nos coloca necessariamente além de qualquer forma de vida determinada). Trata-se, para Rancière, de duas lógicas diferentes, de duas dimensões diferentes: a das relações de poder e a das verificações da igualdade.

A minha posição atual é distanciar-me desse tipo de pensamento: não é questão de reapropriar-nos de uma capacidade que se encontra alienada e que constitui o poder do capitalismo. O poder é, realmente, a coletivização da capacidade que já possuímos, [a capacidade de] criar uma rede específica de relações igualitárias. Para mim, portanto, esse é o ponto principal: diz respeito ao modo em que pensamos a relação entre a pressuposição da igualdade e a ideia de uma possível inteligência coletiva (RANCIÈRE; POWER, 2010, p. 81).

Para Rancière, a política exige renunciar à fé nos princípios que pressupõe o novo materialismo histórico (mais imaterial que nunca): as formas de vida produzidas por um sistema de dominação nunca são mais do que a vida desse sistema, nenhuma sociedade desigual, nenhuma partilha policial do sensível carrega em si qualquer sociedade igualitária. As multidões não nascem da sua desagregação (de nenhuma das suas partes) nem constituem a subjetividade emergente de um processo histórico global. Na mesma medida que os campos, o Império está aquém da política, que bem pode prescindir de tais superstições. 
Pura contingência que amaça toda a ordem social ${ }^{10}$, a política é menos previsível e mais precária.

[A política] não se funda em natureza alguma das coisas, nem se encontra garantida por nenhuma forma institucional. Não é sustentada por necessidade histórica alguma nem sustenta nenhuma. Não se encontra confiada senão à constância dos seus próprios atos (RANCIÈRE, 2005, p. 106).

A emancipação depende para Rancière da nossa desincorporação em relação às partilhas policiais nas quais vivemos, encontra-se associada a uma especial forma de subjetivação. Mas trata-se de um processo de desidentificação e não de um processo de individuação, de um processo de dessujeição e não de instituição de novas formas de subjetividade ${ }^{11}$. Noutras palavras, trata-se da manifestação de uma diferença (entre uma subjetivação e uma identificação), de um distanciamento (em relação às partes reconhecidas na divisão do comum), logo, de um movimento de dessubjetivação, enquanto condição de possibilidade da instauração de uma comunidade, mesmo que seja apenas sob a forma do litígio sobre a comunidade e sobre a igualdade que pressupõe toda ordem desigualitária. Problemática comunidade (porque pressupõe a igualdade mas só existe pela divisão ${ }^{12}$ ) que é colocada a prova (verificada) caso a caso, mas da qual não se deduz conteúdo nenhum, forma de vida nenhuma, individuação alguma.

10 "Pois o fundamento da política, se não é natureza, não é tampouco convenção: é ausência de fundamento, é a pura contingência de toda ordem social. Há política simplesmente porque nenhuma ordem social está fundada na natureza, porque nenhuma lei divina ordena as sociedades humanas" (RANCIËRE, 1996, p. 30).

11 '"Mulher' em política é 0 sujeito de experiência — 0 sujeito desnaturado, desfeminizado — que mede a distância entre uma parcela reconhecida — 0 da complementaridade sexual — e uma ausência de parcela. 'Operário', ou melhor 'proletário', é da mesma forma o sujeito que mede a distância entre a parcela do trabalho como função social e a ausência de parcela daqueles que o executam na definição do comum da comunidade. Toda subjetivação política é a manifestação de um afastamento desse tipo. A bem conhecida lógica policial que julga que os proletários militantes não são trabalhadores mas desclassificados, e que as militantes dos direitos das mulheres são criaturas estranhas a seu sexo tem, afinal de contas, fundamento. Toda subjetivação é uma desidentificação, 0 arrancar à naturalidade de um lugar, a abertura de um espaço de sujeito onde qualquer um pode contar-se porque é 0 espaço de uma contagem dos incontados, do relacionamento entre uma parcela e uma ausência de parcela" (RANCIÈRE, 1996, p. 48).

12 "A igualdade não é um dado que a política aplica, uma essência que a lei encarna nem um objetivo que ela se propõe atingir. E apenas uma pressuposição que deve ser discernida nas práticas que a põem em uso" (RANCIÈRE, 1996, p. 45). 
A política não tem objetos próprios, nem sujeitos próprios, nem sequer questões próprias (RANCIÈRE, 1996, p. 44). A política é simplesmente a instituição de um litígio: não dá lugar à instauração de um novo poder constituinte, apenas coloca em causa, torce, força a reconfiguração da ordem policial existente.

A atividade política é a que desloca um corpo do lugar que lhe era designado ou muda a destinação de um lugar; ela faz ver o que não cabia ser visto, faz ouvir um discurso ali onde só tinha lugar o barulho, faz ouvir como discurso o que só era ouvido como barulho (RANCIÈRE, 1996, p. 42).

Em resumo, a defesa de uma noção de política, como interrupção eventual (fugaz, intempestiva) dos regimes policiais existentes, leva Rancière a se opor às tentativas de pensar a política na encruzilhada entre o poder e a vida, seja de um modo niilista, seja de um modo revolucionário. Em ambos os casos, Rancière encontra a mesma deriva ontológica, a mesma sobredeterminação ontológica da política, quero dizer, o mesmo perigo: porque, mesmo se tratando de ontologias da vida, ambas conduzem, não no sentido de uma maior compreensão da política, mas no sentido da dissolução da desordem política na ordem filosófica, na postulação dos princípios que pretendem regula seu espaço ao mesmo tempo que projetam a sua exterioridade.

Tal é o horizonte da denúncia da fundação da subjetividade política numa ontologia da vida ou da existência, que Rancière identifica por igual nas distinções entre vida qualificada e vida nua em Agamben, vida alienada e vida recuperada em Negri, e, mais profundamente, entre animal laborans e homo politicus em Arendt. Para Rancière, pensar a política corretamente (e distingui-la da polícia) implica fazer um movimento de desontologização, recusando deduzir a política de qualquer forma de ontologia (CHAMBERS, 2011, p. 18).

Por outro lado, como já notamos, e reforçando os argumentos contraontológicos, a crítica de Rancière ao biopoder, e, especialmente, àqueles que pretendem conduzir essa análise no sentido de uma biopolítica, passa por uma circunscrição contraintuitiva da própria noção 
de política, que a desliga completamente das questões associadas à instituição do poder, a organização do estado, a articulação do social, a arbitragem do debate sobre a coisa pública etc. (aspectos todos que dizem apenas respeito, segundo Rancière, à partilha policial do sensível) ${ }^{13}$.

Isso não significa que Rancière reste toda importância à análise crítica da ordem policial nas nossas sociedades (noutras palavras, à política tal como é compreendida ordinariamente). De fato, na medida em que algum tipo de ordem policial (uma certa constituição simbólica do social) é inevitável, na medida em que não é possível pensar a instituição histórica plena da igualdade ou da liberdade (não há fora absoluto em relação à ordem policial), Rancière desenvolve instrumentos críticos para avaliar, desde dentro, os regimes históricos nos quais vivemos. Quero dizer que Rancière não remete a partilha policial do sensível a um plano de indefinição onde tudo é equivalente, onde tudo vale por igual:

Há a polícia menos boa e a melhor - não sendo a melhor, aliás, a que segue a ordem supostamente natural das sociedades ou a ciência dos legisladores, mas a que os arrombamentos da lógica igualitária vieram na maioria das vezes afastar de sua lógica "natural". A polícia pode proporcionar todos os tipos de bens, e uma polícia pode ser infinitamente preferível a uma outra (RANCIÈRE, 1996, p. 43).

Agora, mesmo se é possível os regimes policiais serem avaliados, contestados, expostos ao risco da política, nada disso muda o fundamental: inclusive sendo gentil e amável, a ordem policial "continua sendo, mesmo assim, o contrário da política, e convém circunscrever o que cabe a cada uma delas" (RANCIÈRE, 1996, p. 43).

Num sentido similar, tentando delimitar uma noção da esquerda, Deleuze afirmava não existir governo de esquerda, argumentando que a própria questão do governo não era uma questão da esquerda: “Não é que não existam diferenças nos governos. O que pode existir é um governo favorável a algumas exigências da esquerda. Mas

13 Para uma aproximação à singularidade do deslocamento conceitual proposto por Rancière em relação às noções de política e democracia, ver o texto introdutório de CHAMBERS, S. Police and oligarchy. In: DERANTY, J-P. Jacques Rancière: key concepts. Durham: Acumen, 2010. p. 57-68. 
não existe governo de esquerda, pois a esquerda não tem nada a ver com o governo" (L'ABÉCÉDAIRE, 2004). Rancière retomará essa fórmula polêmica; dirá: "Não há, propriamente, governo democrático. O governo é sempre exercido por uma minoria sobre uma maioria" (RANCIÈRE, 2005, p. 59). A estrita separação da política da polícia proposta por Rancière responde à mesma preocupação manifestada por Deleuze (associada, pela sua vez, à distinção da história e do devir, do maior e do menor), e seguramente está ligada igualmente a eventualização da política, isto é, a sua inscrição numa ontologia do acontecimento ${ }^{14}$.

Porque a política é rara para Rancière. A política acontece, ocorre, tem lugar cada vez que a lógica da ordem policial dominante é desafiada em nome de um princípio irracional e irrazoável (logo, não fundante): a igualdade da parte dos sem parte como comunidade de um litígio. E, quando a política acontece, a divisão da comunidade em suas partes desiguais, a ordem da dominação de umas partes sobre outras é interrompida por um litígio que é comum aos que têm parte e aos que não têm parte.

é também mediante a existência dessa parcela dos sem-parcela, desse nada que é tudo, que a comunidade existe enquanto comunidade política, ou seja, enquanto dividida por um litígio fundamental, por um litígio que afeta a contagem de suas partes antes mesmo de afetar seus 'direitos' (RANCIÈRE, 1996, p. 24-27).

A política tem lugar a partir dessas cenas litigiosas, mas não institui nada, não pode, fora dessa paradoxal comunidade do litígio sobre a conta das partes, que cintila nas trevas das relações desiguais. Fora dessa instituição, não há política (RANCIÈRE, 1996, p. 27-47). Se essas cenas de emancipação, se essas subjetivações procuram institucionalizar-se de outra forma (mais substancial), só podem dar lugar a novos estados de dominação.

14 Rancière vai nisso ao encontro de outras formas de pensamento contemporâneo que fazem da noção de acontecimento e da eventualização da história as chaves de uma compreensão renovada da política; PELLEJERO, E. As novas aventuras da dialética: Holloway, Guattari, Virno. Cadernos de Ética e Filosofia Política, n. 13, 2009.

Rev. Filos., Aurora, Curitiba, v. 25, n. 37, p. 35-55, jul./dez. 2013 
Isso quer dizer que não existe sempre política. Ela acontece, aliás, muito pouco e raramente. O que comumente se atribui à história política ou à ciência do político na verdade depende, com frequência muito maior, de outras maquinarias, que por sua vez provêm do exercício da majestade, do vicariato da divindade, do comando dos exércitos ou da gestão dos interesses. Só existe política quando essas maquinarias são interrompidas pelo efeito de uma pressuposição que lhes é totalmente estranha e sem a qual, no entanto, em última instância, nenhuma delas poderia funcionar: a pressuposição da igualdade de qualquer pessoa com qualquer pessoa, ou seja, em definitivo, a paradoxal efetividade da pura contingência de toda ordem (RANCIÈRE, 1996, p. 31).

Estabelecida a singular posição de Rancière, em todo o caso, devemos nos perguntar se, em sua vontade de combater a redução da política à questão do exercício do poder, e as superstições ontoteológicas sobre as quais se fundam os projetos contemporâneos que perseguem a articulação da disrupção política com a fundação de um novo poder constituinte, Rancière não fica aquém das nossas expectativas, e dos problemas (sempre em aberto) que levanta o sonho da instituição de uma ordem menos absurda.

A preservação da política, como interrupção igualitária das partilhas policiais desigualitárias, pode constituir um conceito-chave para manter uma reserva crítica indispensável perante os regimes oligárquicos (mais ou menos duros) nos quais estamos condenados a viver (RANCIÈRE, 2005, p. 79), logo, um espaço para continuar a pensar a emancipação universal, em condições nas quais até a nossa vida biológica aparece inscrita nas malhas do poder. Porém, o que se resigna nessa reserva é muito, a começar pela necessidade premente de encontrar uma forma consistente de ligar os momentos de desincorporação política à instituição de formas menos desigualitárias de constituição simbólica do social.

Num artigo de 2010, Maurizio Lazzarato assinalava que isolar o ato político como tal, na forma como faz Rancière, comporta o risco de falhar a especificidade do poder capitalista, que agencia numa articulação complexa a divisão desigualitária da sociedade e a produção 
de modelos de existência ou formas de vida (LAZZARATO, 2010). Lazzarato sugeria que, na medida em que o capitalismo contemporâneo faz da vida e da subjetividade objetos privilegiados dos seus investimentos, a mediação ética (no sentido da constituição de um ethos, da formação de um sujeito) resulta imprescindível para cobrir a distância entre a impugnação da ordem policial e a articulação de agenciamentos que permitam amadurecer as subjetivações políticas, conjugando a transformação do mundo com a transfiguração da vida e a transvaloração de todos os valores (para o qual considera que os últimos cursos de Foucault continuam a ser uma referência imprescindível).

Na leitura foucaultiana [...] a igualdade constitui uma condição necessária, mas não suficiente, da política. [...] A ação política se produz no quadro das 'relações paradoxais' que a igualdade mantém com a diferença, cujo resultado é a produção de novas formas de subjetivação e de singularidade (LAZZARATO, 2010).

Evidentemente, a reconsideração que Lazzarato propõe dos processos de subjetivação desde uma perspectiva foucaultiana (à qual Rancière restara toda importância) se apoia na convicção de que a reconfiguração da vida (individual e coletiva) constitui o reto por antonomásia das lutas políticas (LAZZARATO, 2006). Nas novas condições econômicas e políticas, no atual estado da situação, isto, é, na partilha policial dominante, a igualdade não exige para Lazzarato apenas sua verificação, mas sua invenção. A política deve desbordar o reconhecimento (sempre conflitivo) da igualdade, em direção à criação de novas formas de vida capazes de escapar ao biopoder, de lhe resistir por meio de uma dobra das relações de poder instituídas nas próprias formas da subjetividade, dando lugar a uma verdadeira biopolítica revolucionária.

O "bios", a "existência", a "vida" não são conceitos vitalistas aos quais poderiam opor-se os conceitos da divisão política do demos, mas domínios onde se exerce a microfísica do poder e sobre os quais há luta, litigio, sujeições e subjetivações (LAZZARATO, 2010).

Rev. Filos., Aurora, Curitiba, v. 25, n. 37, p. 35-55, jul./dez. 2013 
Posto isso, a crítica que Lazzarato dirige a Rancière não desconhece certos mal-entendidos: a começar pela assimilação do princípio de igualdade à pressuposição de uma exterioridade em relação às relações de poder (ideia incompatível com a noção da política para Rancière), passando pela acusação de logocentrismo dirigida à lógica do desentendimento (quando o certo é que a desincorporação política excede claramente, para Rancière, a questão do logos e se desenvolve no quadro do que ele denomina de estética primeira), e concluindo com a redução polémica das diversas análises de casos concretos propostas por Rancière às suas definições teóricas da política.

No fundo, como admite o próprio Lazzarato, o que se encontra em jogo são "duas concepções radicalmente heterogêneas da subjetivação política" (LAZZARATO, 2010): uma apontando à verificação política da igualdade, outra dependente da diferenciação ética dos sujeitos. O suplemento ético às práticas políticas que propõe Lazzarato na trilha aberta por Foucault implica que a luta por outro mundo possível só pode passar pela constituição de uma vida diferente, enquanto que, para Rancière, a subjetivação política não se encontra associada a nenhuma forma de ethos coletivo tomando a voz (RANCIÈRE, 1996, p. 48) - pelo contrário, o suplemento político à estruturação do mundo comum a partir da diferenciação da vida implica, para Rancière, que a luta tem lugar ao nível dos artifícios da igualdade, isto é, das novas formas de representação do "mundo dado" efetuadas pelos sujeitos políticos, que não legitimam uma outra vida, mas configuram um mundo comum diferente (RANCIÈRE, 2010, p. 76).

Um sujeito político não é um grupo que "toma consciência" de si, se dá voz, impõe seu peso na sociedade. E um operador que junta e separa as regiões, as identidades, as funções, as capacidades que existem na configuração da experiência dada, quer dizer, no nó entre as divisões da ordem policial e o que nelas já se inscreveu como igualdade, por frágeis e fugazes que sejam essas inscrições (RANCIÈRE, 1996, p. 52).

Todavia, enquanto a interrupção política se encontra imediatamente associada à afirmação da emancipação universal (a parte 
dos sem parte é a parte de todos, o princípio de um processo de subjetivação que supera todas as divisões, de uma conta não totalizável que separa a comunidade política da sua partilha policial ${ }^{15}$ ), a afirmação ética é sempre singular e posterga o momento político de articulação das diferenças (um movimento de movimentos é uma necessidade assumida, mas a lógica ethopoiética não nos permite entrever como poderia ser articulado, ficando limitada às suas manifestações singulares).

Em última instância, deparamo-nos com perspectivas que focam os impasses das lutas políticas contemporâneas desde ângulos opostos, e cuja avaliação crítica constitui para nós uma exigência que não podemos postergar.

Por um lado, não é possível negligenciar a política das afirmações igualitárias, cujo correlato é a instituição de "um universal polémico" (RANCIÈRE, 1996, p. 13), compreendido nas cenas de desincorporação da ordem policial descritas por Rancière (elas oferecem um horizonte, precário mas imprescindível, na dispersão das lutas nas quais nos vemos involucrados no dia a dia). Por outro lado, na medida em que esse horizonte igualitário não é instituível numa ordem qualquer, parece imprudente desatender o paciente trabalho ethopoiético de construção de territórios existenciais - eles fornecem um espaço diferencial, frágil mas consistente, onde os resultados das alterações produzidas pelos atos de (des)subjetivação política eventualmente podem amadurecer, opondo uma resistência temporária à cooptação deles pelos dispositivos de poder ${ }^{16}$.

Não quero dizer com isso que as duas lógicas se complementem (isso significaria ignorar a vontade e a inteligência que os seus

15 "O proletariado não é uma classe mas a dissolução de todas as classes, e nisso consiste sua universalidade, dirá Marx [...]. A universalidade da política éa de uma diferença a si de cada parte e a do diferendo como comunidade" (RANCIÈRE, 1996, p. 33).

${ }_{16}$ Num artigo publicado recentemente em espanhol, Etienne Tassin coloca isto último de forma contundente: "Si las relaciones paradójicas entre igualdad y diferencia no pueden inscribirse ni en una constitución, ni en leyes, si no pueden ser enseñadas ni aprendidas, sino solamente experimentadas, entonces la cuestión de las modalidades del actuar juntos se vuelve fundamental. ¿Qué pasa durante la toma de la palabra, después de ella? ¿Cómo este acto de diferenciación vuelve, no solamente sobre el que lo enuncia, sino también sobre aquel que lo acepta? Lo cual equivale a preguntar: ¿cómo se forma una comunidad ligada por la enunciación y el artificio que no esté cerrada por su propia identificación, sino abierta a la diferenciación ética?" (TASSIN, 2012, p. 42).

Rev. Filos., Aurora, Curitiba, v. 25, n. 37, p. 35-55, jul./dez. 2013 
autores colocaram em seus trabalhos). Entre a impugnação e a reconfiguração do mundo comum, ainda se impõem uma série de questões fundamentais, que a práxis política e o trabalho teórico não deixam de levantar (a começar pela pergunta sobre a possibilidade de agenciar coletivamente a vida sem produzir pelo mesmo movimento novas relações de dominação), num exercício necessariamente paciente, que está sempre por recomeçar ${ }^{17}$.

Nesse sentido, se no começo assinalei que, na aproximação de Rancière, aquém da biopolítica tinha pelo menos dois sentidos, penso que agora, à conta do exposto, podemos postular um terceiro sentido dessa expressão. Porque, na tentativa de repensar a política além das relações de poder, sem recair nos credos progressistas da Modernidade nem abandonar-se ao luto infinito dos seus ideais emancipatórios, quiçá Rancière resigna demasiado, pagando pela consistência teórica da sua posição crítica com o balizamento da sua sensibilidade política, que significativamente deixa de lado certos movimentos que agitam nosso mundo, suas apostas e suas expectativas $^{18}$.

Mas aquém designaria, então, menos uma insuficiência da sua obra que uma tarefa, que nem os conceitos de Foucault, nem os reparos de Lazzarato podem resolver por nós; uma tarefa na qual - acredito - todos aqui nos encontramos involucrados, não apenas como pensadores, mas também como homens e mulheres que em todo o momento estão dispostos a colocar à prova (a verificar) a igualdade das inteligências, logo, a lutar pela emancipação da vida das malhas nas quais é hoje canalizada, explorada, ou abandonada a morrer.

17 "A persistência desse dano é infinita porque a verificação da igualdade é infinita e porque a resistência de toda ordem policial a essa verificação é principal" (RANCIÈRE, 1996, p. 51).

18 Tassin assinala, nesse sentido, a falha do aparelho conceitual de Rancière perante certos fenômenos políticos contemporâneos, como a luta as lutas dos sem-papeis que, à imagem das lutas dos sem-direitos ou sem-Estado pelas quais Arendt demostrou interesse, onde são centrais determinados processos de subjetivação (TASSIN, 2012, p. 49). 


\section{Referências}

CASTRO, E. El vocabulario de Michel Foucault: un recorrido alfabético por sus temas, conceptos y autores. Buenos Aires: Universidad de Quilmes, 2004.

CHAMBERS, S. Introduction to "The lessons of Rancière". 2011. Trabalho apresentado no University of Virginia Political Theory Colloquium, 18 nov. 2011. Disponível em: <http://www.publicaffairs.virginia.edu/drupal/politics/system/ files/Chambers_UVA_Lessons_of_Ranciere.pdf $>$. Acesso em: 5 dez. 2012.

CHAMBERS, S. Police and oligarchy. In: DERANTY, J-P. Jacques Rancière: key concepts. Durham: Acumen, 2010. p. 57-68.

FOUCAULT, M. Dits et écrits. Paris: Gallimard, 1994.

HEMEL, E.V. D. Included but not belonging - Badiou and Rancière on human rights. Krisis - Journal for contemporary philosophy, n. 3, 2008. Disponível em: $<$ http://krisis.eu/content/2008-3/2008-3-03-hemel.pdf>. Acesso em: 2 out. 2013.

L'ABÉCÉDAIRE de Gilles Deleuze. Produção e realização: Pierre-André Boutang. Participantes: Gilles Deleuze; Claire Parnet. Paris: Editions Montparnasse, 2004. 3 DVDs (453 min.). Primeira transmissão realizada pelo Canal Arte, Paris, 1996.

PELLEJERO, E. A lição do aluno: uma introdução à obra de Jacques Rancière. Saberes, v. 2, n. 3, 2009. Disponível em:<http://www.periodicos.ufrn.br/index. php/saberes/article/view/574/523>. Acesso em: 1oout. 2013.

LAZZARATO, M. Enonciation et politique - Une lecture parallèle de la démocratie: Foucault et Rancière. 2010. Trabalho apresentado na sessão de 25 de fevereiro de 2010 da Université ouverte 2009-2010: La vie "militante" dans la politique et dans l'art. Disponível em: $<$ http://lesilencequiparle.unblog. fr/2010/04/14/enonciation-et-politique-une-lecture-parallele-de-la-democratie-foucault-et-ranciere-maurizio-lazzarato>. Acesso em: 5 dez. 2012.

LAZZARATO, M. Del biopoder a la biopolítica. Multitudes, n. 1, mar. 2000. Disponível em: <http://multitudes.samizdat.net/Del-biopoder-a-labiopolitica>. Acesso em: 2 out. 2013.

Rev. Filos., Aurora, Curitiba, v. 25, n. 37, p. 35-55, jul./dez. 2013 
RANCIÈRE, J.; POWER, N. Interview with Jacques Rancière. Ephemera, v. 10, n. 1, 2010. Disponível em: <http://www.ephemerajournal.org/sites/default/files/10-1rancierepower.pdf> Acesso em: 5 dez. 2012.

RANCIÈRE, J. Biopolítica ou política? Urdimento: Revista de Estudos em Artes Cênicas, n. 15, out. 2010. Disponível em: <http://www.ceart.udesc.br/ ppgt/urdimento/2010/Urdimento_15.pdf> Acesso em: 1ํo out. 2013.

RANCIÈRE, J. O desentendimento: política e filosofia. Trad. Ângela Leite Lopes. São Paulo: Editora 34, 1996.

RANCIÈRE, J. Ten theses on Politics. Theory and Event, v. 5, n. 3, 2001. Disponível em: <http://muse.jhu.edu/journals/theory_and_event/ v005/5.3ranciere.html>. Acesso em: 2 out. 2013.

RANCIÈRE, J. Who is the subject of the rights of man? South Atlantic Quarterly, v. 103, n. 2-3, p. 297-310, 2004.

RANCIÈRE, J. La haine de la démocratie. Paris: La Fabrique Éditions, 2005.

TASSIN, E. De la subjetivación política. Althusser/Rancière/Foucault/Arendt/ Deleuze. Revista de Estudios Sociales, n. 43, 36-49, 2012.

Recebido: 10/06/2013

Received: 06/10/2013

Aprovado: 14/09/2013

Approved: 09/14/2013 